\title{
Firmino Costa, un intelectual de la República y sus propósitos educativos $(1907-1937)^{1}$
}

\author{
Juliana Cesário Hamdan ${ }^{2}$ \\ Universidad Federal de Ouro Preto (Brasil) \\ julianach@globo.com
}

Recepción: 06/03/2013

Evaluación: 10/10/2013

Aceptación: 13/12/2013

Artículo de Reflexión

DOI: http:/ / dx.doi.org/ 10.9757/Rhela.22/08

\section{RESUMEN}

El presente artículo pretende analizar la actuación del educador Firmino Costa, nacido en Minas Gerais, al retomar sus antecedentes históricos que se localizan en la base de las formas de su actuación política e intelectual. Para este análisis, recurrimos al trabajo de Alonso (2008), ${ }^{1}$ Oliveira $(1999)^{2}$ y Carvalho (2003), ${ }^{3}$ consideramos las expresivas contribuciones para su comprensión en relación con la historia e ideas que circularon en este periodo, comprendido entre los años que antecedieron a las primeras décadas de la Proclamación de la República en Brasil (I889). Las tres obras, pese a que se escribieron a partir de objetos y objetivos distintos, refutaron interpretaciones que, por un lado, tratan el escenario intelectual de la República por medio de tipologías de intelectuales, que estarían absorbiendo pasivamente las teorías europeas y norteamericanas. Y, por otro lado, las que son marcadas por estudios que enfatizan las acciones individuales, empeñadas en llevar adelante sus

1 Ángela Alonso, Idéias em movimento: a geração de 1870 na crise do Brasil-Império. (São Paulo: Paz e Terra, 2002), 94.

2 Lúcia Lippi Oliveira, A questão nacional na Primeira República, (São Paulo: Editora Brasiliense, 1990), 189.

3 José Murilo de Carvalho. A formação das almas. O imaginário da República no Brasil, (São Paulo: Companhia da Letras, 1990), 152. banderas ideológicas. Al contrario, los autores entienden que los sujetos están inmersos en determinado entorno cultural, constituido por las redes de sociabilidad y por el repertorio de ideas en circulación y, por eso mismo, tienen formas distintas de actuación política e intelectual. Y ese escenario condiciona, en gran medida, las posibilidades de actuación.

Así, este artículo busca establecer conexiones entre algunos elementos del escenario cultural, presentes en los años que antecedieron y en los que sucedieron a la República, relacionándolos a las formas de actuación política e intelectual que informan la acción educacional del educador minero. Ese movimiento analítico, por su vez, exigió que recorriésemos a algunas de las formulaciones teóricas de Antonio Gramsci, en lo que se refiere a los sentidos de actuación de los intelectuales, como forma de comprenderlos a partir del contexto y de las posibilidades de actuación que permitían al educador minero la realización de sus intentos.

Palabras clave: Revista Historia de la Educación Latinoamericana, intelectual de la República de Brasil, educador Firmino Costa, ideas en circulación.

1 Este artículo fue preparado como un desarrollo de una investigación doctoral desarrollada en 2007 en la Universidad Federal de Minas Gerais - UFMG.

2 Ph.D en Educación de la Universidad Federal de Minas Gerais, profesor adjunto de la Universidad Federal de Ouro Preto UFOP, Departamento de Educación - DEEDU - Pertenece al Grupo de Investigación de Historia de la Educación Historiar/GEPHE, da Universidad Federal de Minas Gerais, UFMG, Facultad de Educación. 
Firmino Costa: The Republic of an intellectual and educational purpose (1907 - 1937)

\author{
Firmino Costa: Um intelectual da República e o \\ propósito educativo (1907 - 1937)
}

\section{RESUMO}

The purpose of this article is to analyse the performance of Firmino Costa an educator from Minas Gerais State, by taking historical feedebacks which are on the basis of ways and means of his political and intelectual roles. We have, for this analisys, looked over the works of Alonso 2008, of Oliveira 1999 and Carvalho 2003, by considering they bring up relevant contributions for the understanding of the histories of vivid ideas present between precedent years and the first decades of the Republic Proclaimation. The three works eventhough as of distinct objects and objectives, reject interpretation that, on one aspect, deal with the intelectual Republic ambience by means of intelectual tipologies clivages which would have been passively absorving european and american theories and, on the other hand, the ones that are stressed by studies that approach individual actions commited to the holding on ahead its ideological collors. These authors, on the contrary, understand that individuals are involved in determined cultural ambiences built up from sociability nets and by the running ideas repertory and, as to this very circusntance, they have different political and intelectual ways of acting by in a large scale, conditioning these factors to the possibilities of acting.

So in this article the effort is trying to fix connectives amomg some elements of cultural ambience within the previous years to the Republic and relating them to the political and intelectual ways of acting that have enabled the educational information for the educator from Minas Gerais State. This analitycal movement, by itself had demanded that we should have resorted to some of the theoretical formulations of Antonio Gramsci 1975 as to the action senses of the intellectuals, as means of understanding them from the context and as the possibilities of acting are concerned, that have enabled the educator from Minas the achieving of their intents.

Key words: Journal of the History of American Education, intellectual of the Brazilian Republic; educator Firmino Costa; ideas in circulation.
Neste artigo pretende-se analisar a atuação do educador mineiro Firmino Costa, retomando antecedentes históricos que estão na base das formas de sua atuação política e intelectual. Para esta análise, recorremos aos trabalhos de Alonso (2008), de Oliveira (1999) e de Carvalho (2003), considerando que trazem expressivas contribuições para a compreensão acerca das histórias das ideias em circulação entre os anos que antecederam e as primeiras décadas da Proclamação da República. As três obras, ainda que a partir de objetos e objetivos distintos, rejeitam interpretações que, por um lado, tratam a ambiência intelectual da República por meio de clivagens de tipologias de intelectuais, que estariam absorvendo passivamente as teorias europeias e americanas e, por outro, as que são marcadas por estudos que focam as ações individuais, empenhadas em levar à frente suas bandeiras ideológicas. Pelo contrário, esses autores entendem que os sujeitos estão imersos em determinadas ambiências culturais, constituídas pelas redes de sociabilidades e por repertório de ideias em circulação e, por isso mesmo têm formas distintas de atuação política e intelectual. Condicionando, esses fatores em grande medida, as possibilidades de atuação.

Assim, neste artigo buscam-se estabelecer conexões entre alguns elementos da ambiência cultural presentes nos anos que antecederam e nos que sucederam a República, relacionando-os às formas de atuação política e intelectual, que informaram a ação educacional do educador mineiro. Esse movimento analítico, por sua vez, exigiu que recorrêssemos a algumas das formulações teóricas de Antonio Gramsci (1975), no que se refere aos sentidos da atuação dos intelectuais, como forma de compreendê-los a partir do contexto e das possibilidades de atuação que permitiriam ao educador mineiro a realização de seus intentos.

Palavras-chave: Revista de História da Educação Latino-americana, intelectual da República brasileira, educador Firmino Costa, ideias em circulação. 


\section{INTRODUCCIÓN}

\section{Firmino Costa y su actuación política e intelectual}

Toda la formulación teórica de Antonio Gramsci, pensador italiano del siglo pasado, partió del análisis de contextos históricos específicos y esa "metodología" presente en su forma de investigar es una condición para la adopción de una de sus categorías en la comprensión de otros contextos. Si bien, si esto es verdad, sus categorías estarían irremediablemente vinculadas a los respectivos contextos que las originaron y su valor heurístico para la inteligibilidad de otras realidades. Esa es una dificultad que enfrentamos por considerar que Firmino Costa, en la condición de intelectual y político brasileño, contemporáneo de Gramsci, pudiese ser capturado por medio de la categoría del intelectual orgánico.

Para dimensionar esa dificuldad, Carlos Eduardo Vieira ${ }^{3}$ apunta en dos direcciones. Por un lado, hay la exigencia de recuperar el contexto de producción de la categoría por el pensador italiano y, con eso, la aprensión del sentido por él atribuida. Aun en esa misma dirección, re-contextualizarla también en el propio proyecto de investigación del filósofo, como una forma de conectarla al sistema mayor de las categorías por él formuladas, las cuales están intrínsecamente relacionadas. Por otro lado, el objeto a ser analizado por medio de la categoría, a su vez, también necesariamente deberá ser reconocido y cualificado por medio del contexto que lo informa.

Desde nuestro modo de ver, el primer aspecto por él apuntado representaría un trayecto analítico fecundo, en la medida en que evitaría los riesgos de una adopción anacrónica y, al mismo tiempo, genérica de la categoría en cuestión. Sin embargo, justificamos de antemano que ese ejercicio extrapolaría mucho nuestro trabajo y, por eso, lo haremos de forma bastante abreviada. En relación con el segundo, salimos en nuestra defensa argumentado que nuestro objeto de estudio, sea cual sea la dimensión política e intelectual del educador Firmino Costa, será tratado en los tópicos siguientes, a partir de sus condicionantes históricos, esto será insertado y analizado según las llaves analíticas propias para su contexto. De ese modo, siguiendo las orientaciones de Vieira, estaríamos respaldados.

3 Carlos Eduardo Vieira, “Conhecimento histórico e arte política no pensamento de Antonio Gramsci”, em Pensadores Sociais e História da Educação, organizado por Luciano Mendes de Faria Filho, x-x. (Belo Horizonte: Autêntica, 2005), 63 - 65. 
En ese punto, cabría interrogarnos sobre lo que nos lleva a insistir en la adopción de esa categoría y el sentido de hacerla. Podríamos usar el argumento de que el sistema de pensamiento de Gramsci, a partir de las últimas décadas de los años setenta, ha sido ampliamente adoptado por diversos intelectuales para comprender la realidad brasileña, ${ }^{4}$ sobre todo en los años treinta. Todavía esta afirmación no parece suficiente.

Nuevamente es Vieira quien viene a nuestro auxilio, cuando presenta dos argumentos para la adopción de las categorías gramscianas en investigaciones históricas. Primero, aun que esté articulado a una crítica en relación con una adopción no histórica de los conceptos gramscianos, presente en algunos de los estudios arriba referidos, para Vieira es deber del historiador, en la perspectiva historicista del filósofo italiano, tanto operar a partir de lo empírico, como apropiarse de instrumentos de análisis, esto es, de las categorías. En ese sentido, en el entendido de articular el campo de la historia con las concepciones de Gramsci, Vieira sustenta que,

\section{[...] su método de elaboración conceptual [...] produjo sus herramientas heurísticas por medio de un proceso de re-significación de conceptos in- corporados de otras teorías sociales. En la tensión entre lo empirico y la teoría, Gramsci no necesitó en reorganizar el plano abstracto en relación con el plano de la realidad. ${ }^{5}$}

Esa formulación de Vieira sobre la adopción de las categorías de Gramsci como instrumentos de análisis para objetos históricos, aunque permanezca la exigencia de su contextualización, ya nos ofrece una mayor significación con relación a nuestra elección por la categoría del intelectual orgánico para multiplicar el pensamiento político e intelectual del educador Firmino Costa. Sin embargo, es en su segundo argumento que nos sentimos más resguardados, en la medida en que inserta el marco teórico gramsciano como posibilidad fecunda para la historia del intelectual. Segun él,

[...] Gramsci, entre muchas posibilidades que sus escritos encierran, llama la atención para el papel de las ideas y de los intelectuales en la organización de la cultura. No obstante, sugiere una historia de las formas del pensamiento y las de sus protagonistas encarnada en las prácticas sociales. ${ }^{6}$

\footnotetext{
Sobre la difusión de las concepciones de Gramsci en Brasil, consultar Coutinho, (1999 y 1998) y Vieira (2005 y 1999). Vieira, “Conhecimento histórico e arte política..., 83-84. Ibid., 84 .
} 
De hecho, la citación de Vieira sobre la adopción de las categorías de Gramsci para su análisis histórico coincide con el abordaje adoptado para nuestro objetivo, esto es, el papel de las concepciones educacionales de Firmino Costa, como intelectual y político, en el estado de Minas Gerais, en las primeras décadas del siglo XX por medio de sus prácticas educativas. Habiendo establecido esas premisas, podemos dar continuidad a nuestro intento de analizar la configuración del repertorio de conceptos del educador, a la luz de la categoría gramsciana, procurando aprender lo que el filósofo sardo entiende por intelectual orgánico.

\section{El de Gramsci intelectual}

Como una primera pregunta que se presenta en el análisis de la función social de las actividades de los hombres, $\mathrm{Gramsci}^{7}$ en su conocida formulación explica que cuando se distinguen las categorías profesionales entre intelectuales y no intelectuales, se está apenas realizando una mera separación en la cual se atribuye un peso mayor a las actividades visiblemente físicas y motoras, o aquellas elaboraciones prevalentemente intelectuales. Esto porque, efectivamente, esa distinción no existe.

De esa premisa gramsciana se puede inferir que todos los hombres son, en principio, intelectuales, en la medida en que toda actividad humana es también una actividad intelectual, independientemente del tipo de ejercicio profesional que realice, esto es, con una mayor visibilidad de la actividad motora o no. Esto porque "[...] en cualquier trabajo físico, aunque sea lo más mecánico y degradado, existe un mínimo de cualificación técnica, esto es, un mínimo de actividad intelectual creadora". Sin embargo, "[...] existen diferencias entre afirmar que en todas las actividades humanas está presente la dimensión intelectual y que todos los hombres realizan la función de intelectual en la sociedad. Así, todos los hombres son intelectuales, pero no todos ejercen la función social de intelectual" ${ }^{8}$

¿Y qué se podría entender por esa función social de los intelectuales? Primeramente, sería interesante comprender la adopción del término "intelectual". Según Beireb, ${ }^{9}$ hasta los años treinta ningún otro pensador había atribui-

7 Antonio Gramsci. Quaderni del carcere. Cinque Volumi (Torino: Giulio Einaudi Editore. Prima edizione "Nuova Universal Einaudi", 1975), 1516.

8 Ibid., 1516.

9 José Luís Benedichio Beireb, “A função social dos intelectuais", en Gramsci, a vitalidade de um pensamento, editado por Alberto Aggio, (São Pulo: Editora UNESP, 1998), 123. 
do al término la importancia que el filósofo italiano le dio, en el sentido de aprenderlo como un importante instrumento de transformación en el contexto de la sociedad civil o política y sería, por eso, es una de las categorías más originales del sistema gramsciano. Además de esto, su valor heurístico reside en la evidencia de que fue en el examen de realidades concretas que el término fue acuñado, trayendo en su bojar la complejidad de la historia que presenció, a pesar de haber sido un término recientemente formulado.

La génesis teórica del concepto parte de un análisis histórico que remonta desde el nacimiento de la intelligentsia rusa, en los años 1830 a 1840, cuando un grupo de nobles se permiten inmiscuir en los asuntos propios de la corona rusa y, para eso, forman una especie de comité, por medio del cual pasan a analizar los movimientos políticos de entonces. Así, la palabra, originada del latín, fue creada por los rusos y

"[...] definía un nuevo grupo social surgido en Rusia en el siglo XIX, esto es, una camada de individuos cultos y preocupados con los asuntos públicos que, constituida inicialmente por nobles, pasó a tener percepción de si misma como grupo social particular" 10

Sin embargo, fueron los franceses los que se apropiaron del concepto histórico del término intelligentsia y formularon la "palabra 'intelectual' para definir al individuo que integraba ese conjunto". De ese modo, en cuanto intelligentsia, se referiría al colectivo, a un grupo, el término intelectual pasó a referirse a cada uno de los individuos que él formaba. El término ganó mucha notoriedad con la enorme repercusión del Caso Dreyfuss, considerando que grandes nombres de la intelectualidad francesa, tales como Emile Zola, Marcel Proust y otros, se manifestaron a favor de los derechos humanos, cuando defendieron al capitán acusado de alta traición por los franceses. ${ }^{11}$

De los dos casos, Gramsci puede deducir que el lugar social de donde se originaron los intelectuales es determinante respecto a su actuación, esto es, no se puede concebir un intelectual que actúe de forma independiente y excluida del contexto que lo forma y que lo informa. Tanto en un caso, como en el otro, la articulación de los intelectuales presupone una intervención en un contexto específico. $Y$ es precisamente ese contexto que, de cierta manera,

10 Vieira, “Conhecimento histórico e arte política..., 123.

11 Ibid., 124. 
condiciona el sentido de la intervención elegida, la cual ocurrió de forma bien distinta en cada uno de los casos. Para el pensador, la concepción según la cual un intelectual actúa separado del restante de la sociedad, representa una lectura idealista del mundo, eso es, no considera las condiciones materiales y culturales de su producción y, sobre todo, de su apropiación.

Analizando las dos formas de intervención, Gramsci puede aun absorber otra dimensión de la realidad. El contexto social en el cual está inserido, o sea, el lugar de donde habla, y la forma de su articulación con el conjunto de la sociedad, esto es, el sentido de su actuación permite que se pueda añadir más una acepción al término, por medio de la aglutinación de otra palabra. De ese modo, el término "orgánico" adicionado al "intelectual" aparece en el sentido de informar qué tipo de actuación o de articulación que un intelectual realiza con ese grupo de la sociedad. Tanto en el caso de la intelligentsia rusa como en el caso Dreyfuss, hay una intervención de tipo orgánica por medio de la actuación de los intelectuales. Sin embargo, en cuanto a la primera se restringiría a los propios intereses de la nobleza, en la segunda ella presupone una actuación más ampliada y provoca, por eso, algún tipo de movilización en la sociedad civil.

Con la formulación y adopción de la categoría "intelectual orgánico", Gramsci puede de cierta forma, revolucionar la concepción vigente del intelectual, en la medida en que atribuye la función social del organizador. Organizador aquellos hombres que tienen la capacidad de movilizar a otros hombres en torno de una idea, de un ideal, de un movimiento, organizando, así al tejido social de forma diferente. Todavía, lo hacen por medio de una profunda capacidad reflexiva sobre sí mismo y sobre el conjunto de la sociedad. ${ }^{12}$

A pesar de que el lugar social marque el lugar en donde se habla, la capacidad organizativa, tanto de la cultura, como de otras instancias sociales, inherente a la función del intelectual orgánico, no se restringiría a determinados medios o clases sociales, pese a que representa una especie de elite, en el sentido de su función de articulador con las demás clases sociales. Por eso, otra virtud de la categoría sería de resignificación del papel del agente social, que ejerce actividades intelectuales y que, no necesariamente, es oriundo de las camadas privilegiadas, tales como los profesores, los artistas, los militantes políticos, los líderes religiosos, o científicos, dentro de otros. ${ }^{13}$ 
Para llegar a esa formulación, Gramsci analizó diversos contextos históricos, examinando el papel de los intelectuales, en el sentido de propiciar una determinada organización cultural, en relación con diversas instancias sociales: el Estado, la escuela, la prensa y la iglesia, sobre todo, en países en que ya se gestaba algún tipo de revolución. Con eso, él observó que la fuerza organizativa de los intelectuales tiene el poder intrínseco de formar o catalizar una determinada voluntad popular, en dirección a una transformación social. Esa transformación social, por la vía cultural, tiene diferentes perspectivas para diferentes contextos históricos.

En nuestro modo de ver, la teoría gramsciana iluminó nuestro objeto en doble sentido. El primero de ellos se refiere a la unión teórica entre las dimensiones del intelectual y político que informa la actuación del educador. En este trabajo, estamos calificando la acción educativa de Firmino Costa, siempre sobre la perspectiva del intelectual y político, nunca apenas sobre una de las dos categorías. Nuestra intención es por un lado demonstrar cómo, históricamente, esa aglutinación se explicó. Podemos identificar las razones históricas y contextuales brasileñas para entender la actuación de los intelectuales, sobre todo, en la época pre-republicana, pero también, y al mismo tiempo, como fuerza política, una no sería comprendida sin la otra, recíprocamente.

Por otro lado, el análisis que realizamos sobre la trayectoria del educador de Lavras camina al encuentro de la formulación del intelectual orgánico de Gramsci, porque ahí la dimensión política e intelectual de su actuación es sustentada, a su vez, a partir de su articulación con la cultura. Como forma de concluir este tópico, podemos presentar la más sintética elaboración de la categoría encontrada en la obra del filósofo. Según él, el intelectual orgánico es especialista, pues retiene algún conocimiento sobre alguna área y es política, pues ejerce la función de dirigente, en la medida en que usa su conocimiento para organizar alguna instancia social, sobre todo, por medio de la cultura.

Otro aspecto, cuya teoría gramsciana contribuyó de forma expresiva a la comprensión de nuestro objeto, se refiere al énfasis, atribuido por ella, a la cuestión de la organización cultural. Este abordaje nos permite retornar a las prácticas cotidianas del ejercicio del educador, director, profesor, bien como las concepciones de educación que subyacen a esas acciones, en la medida en que implican en acciones sistemáticas, persistentes, de implementaciones 
de estrategias cuidadosamente elaboradas, evaluadas, retomadas, en un continuo ejercicio de persuasión, de convencimiento activo, de envolvimiento de toda una red de sociabilidad, para la ejecución del fin que se pretende. En ese sentido, Gramsci aseguraba que “[...] el modo de ser del nuevo intelectual no puede más consistir en la elocuencia, motor exterior y momentáneo de los afectos y de las pasiones, pero no mezclarse activamente a la vida práctica, como constructor, organizador, [un] 'persuasor permanente'" $[. ..]{ }^{14}$

\section{Actuación de Firmino Costa en el espacio público minero: la ins- trucción pública en primer lugar}

Para comprender la actuación intelectual y política de Firmino Costa en el contexto pre-republicano y en los años subsecuentes, fue importante considerar que, nacido en 1869 , creció sobre las ideas y de los movimientos que antecedieron a la República, inclusive dentro de su propia casa, considerando el posicionamiento político de su padre, de marcada tendencia liberal republicana. Habiendo permanecido algún tiempo en São Paulo, en cuanto estudiaba, también pudo ver más de cerca y con mayor intensidad los debates que acompañaban los últimos suspiros del Imperio que se desmoronaba en la corte vecina. Sin embargo, considerando la experiencia advenida de ese viaje, parecen haber sido las lecturas y las redes de sociabilidad las mayores informantes para la constitución de su repertorio. Es conveniente, en ese punto, interrogar qué lecturas e informaciones existían, antes aun, porque las lecturas e informaciones estaban en circulación en ese periodo.

Al buscar las conexiones de Firmino con las ideas en circulación en el escenario cultural, no estamos intentando afiliarlo artificialmente y póstumamente a una $\mathrm{u}$ otra manifestación cultural o a un determinado sistema de pensamiento, tampoco defender que él pueda haber sido un portavoz de ellas, influenciado por el prestigio cultural que pudiese advenir en los movimientos allí presentes. En nuestra tentativa de identificar algunos de los elementos del repertorio que fueron adoptados por el educador como sustentación de sus acciones, en la forma de una herencia, asimilada activamente, que pueda haber impregnado su forma de pensar y de actuar. De esa forma, la comprensión de ellas nos permitió entender un poco más los posicionamientos del educador.

14 Gramsci, “Quaderni del carcere”, 1515. 
Contra la idea de la pasividad de los sujetos frente a las influencias de determinados sistemas teóricos o de la ausencia de creatividad y originalidad en la apropiación de estos, Michel de Certeau ${ }^{15}$ nos aclarara que no es posible pensar de esa forma, ni tampoco con relación a los propios autores de las ideas y pensamientos en cuestión, porque "todo lugar 'propio' es alterado por aquello que, de los otros, ya se ve en él". De esta forma, las apropiaciones siempre particulares son posibilitadas por medio de "[...] intercambios, lecturas y enfrentamientos que forman sus condiciones de posibilidades, cada estudio particular es un espejo de cien faces (en este espacio los otros están siempre apareciendo), más un espejo partido y anamórfico (los otros se fragmentan y se alteran)".

Cuando pensamos sobre el ambiente intelectual en la entrada a la República brasileña, estamos considerandoquehabía un conjunto deideas en circulación, tanto aquellas oriundas de sistemas teóricos europeos o americanos, como también de la propia estructura de los pensamientos nacionales. De uno o de otro modo, esas ideas eran movilizadas por los actores sociales conforme a la necesidad que exigía. Traducidas tanto en maneras de pensar, como también en las de actuar, o sea, en las prácticas sociales, hicieron parte del repertorio de actuación de los intelectuales y políticos como forma de enfrentamiento de las cuestiones específicas del periodo y del contexto brasileño. Por tanto, al partir de las asertivas de Certeau, resaltamos que no se trataría de adopción pasiva o de mera importación de ideas. Bien al contrario, el conjunto de informaciones con las cuales se operaba fue profusamente alterado por las condiciones de apropiación existente y estaban en constante movimiento de reelaboración y reapropiación por algunos de los actores sociales.

El hecho de que a partir de 1874 Brasil había pasado a recibir y a emitir noticias e informaciones vía cable telegráfico submarino, conectándolo a Europa, a los Estados Unidos y entre las ciudades brasileñas, fue un aspecto que agilizó bastante los procesos de circulación de las informaciones, las cuales hasta entonces llegaban de navío o de tren, con semanas de atraso. Este progreso, sumándose a otros aspectos igualmente relevantes, tal como la posibilidad de una mayor y mas rápida difusión permitida por el desarrollo de los medios de transportes, provocó una serie de modificaciones en la lógica de la producción económica, pero, sobre todo, política e intelectual. Las

15 Michel de Certeau. A invenção do cotidiano. Vol. 1 - Artes de Fazer, (Petrópolis, RJ: Vozes, 1994), 110. 
expresiones del progreso tecnológico, sumadas a los progresos relativos a las tipografías y a la impresión, impactaron en la práctica de los intelectuales y políticos en formación, pues abarataron los costos y ampliaron la edición de diversos títulos. En ese sentido, Ángela Alonso ${ }^{16}$ afirma que "[...] la abertura de librerías, editoras y periódicos intensificó la circulación de la información, expandiendo el universo intelectual mas allá de la elite política"

Paulatinamente, la sociedad civil se amplía y, al menos aquellos que tenían algún recurso cultural y también económico, pasaron a tener acceso a las informaciones y publicaciones, concomitantemente a su producción. Con eso, se observa una participación más cualificada y cada vez mayor de la sociedad civil en el debate sobre los problemas de la época, tanto en términos de nuevos interlocutores, como en términos de la pauta del debate. De ese modo, el origen social de los intelectuales y políticos, hasta entonces asociada obligatoriamente a las elites, comienza a presentarse por medio de un escenario un poco diferente.

Nuevos actores, diferentes entre sí, levantan nuevas voces sobre antiguas cuestiones tales como la esclavitud, la monarquía, la instrucción pública, pero, especialmente, sobre la República, y pasan a buscar formas de expresarse públicamente. Estaba claro que, en el nuevo cuadro social, los intelectuales y políticos que querían hacerse oír podían ser distinguidos apenas por el perfil económico. Eran hijos de diferentes clases sociales y de todas las profesiones: desde pequeños propietarios rurales hasta grandes terratenientes, desde tímidos comerciantes, hasta militares de toda patente. Todavía, deberían necesariamente ser al menos portadores de algunos recursos que posibilitasen la información y, también tornaren públicas sus insatisfacciones.

Si bien no se puede afirmar que Firmino Costa fuese originario de una familia humilde, también no es verdad que formase parte de los sectores más pudientes. Su padre de excombatiente pasó a ser trabajador de la labor agrícola y después propietario de un comercio en Lavras. Pudimos constatar que ellos tenían recursos para financiar en la educación de los hijos, pues Firmino tuvo incluso la oportunidad de ir a São Paulo, para completar sus estudios. Con todo, no llegó a cursar la facultad.

16 Alonso, "Idéias em movimento..., 94. 
La bibliografía sobre la vida de Firmino muestra que su padre había engrosado el coro de los descontentos con la orden Saquarema, sobre todo si consideramos su participación en las diversas revueltas que marcaron el periodo. Así, nos parece que el educador había sido formado sobre la pujanza de las contestatarias presentes sobre el escenario intelectual, a pesar de estar en Lavras.

Un lema que permeó buena parte de los debates de la época, de cierta forma, presente en las revueltas, es la cuestión nacionalista que, pese a que se haya presentado por medio de diversos matices, convergía para la construcción de la identidad y de la alteridad nacional, perfiladas por la preocupación con la salvación nacional. En ese sentido, si no iban a los campos de batallas, los intelectuales de la época se atribuían el papel de responsabilidad por la creación y preservación de una tradición que justificase y, al mismo tiempo, sustentase sus descontentamientos y banderas. Así, "el ideario nacionalista" fue una construcción elaborada por los intelectuales y a ellos debe ser atribuida, en grande parte, su difusión. Según, Lúcia Lippi Oliveira, ${ }^{17}$

\section{[...] independientemente de su origen de clase, de su formación bachare- lesca o especializada, se mantuvieron ocupados en "pensar" en el Brasil y en proponer caminos para la salvación nacional. Al actuar en la cons- trucción de consciencias colectivas, los intelectuales consideran imbui- dos de una misión y procuraron difundir sus propuestas.}

Lo que caracterizaría predominantemente el clima de contestación presente en el ambiente intelectual prerepublicano eran las restricciones con relación a oportunidades de expresión y de actuación de las nuevas voces sociales que se constituían. La amalgama que unía, principalmente, los más diferentes grupos de contestación al final del siglo XIX fue la insatisfacción con la situación de exclusión que se vivía con relación al statu quo Saquarema, esto es, un régimen cerrado, retrógrado, conservador, sin espacio para nuevos emprendimientos y perspectivas. En ese sentido, ellos no venían de una misma formación académica, ni de un mismo origen social y económico. Eran los intelectuales de todas las clases sociales: desde hijos de altos funcionarios públicos, como de pequeños labradores o de grandes propietarios rurales, militares o comerciantes. Ni eran oriundos prevalentemente de una misma provincia, mas guardaban entre sí una disposición para la contestación.

17 Oliveira, “A questão nacional na Primeira República”, 189 
Dos décadas después, la forma osada y asertiva con la que el educador Firmino Costa desarrollaba su actuación política e intelectual puede haber sido condicionada por el clima de contestación del cual compartía en cuanto se formaba. Del mismo modo, se fueron dando las formas en las que él reivindicaba a sus superiores, aquello que él pensaba de sus derechos para la realización del proyecto educacional. Se mostraba bastante seguro y con un fuerte esbozo teórico de argumentación abierta, tanto para anunciar su adhesión incondicional a la Reforma de João Pinheiro en 1906, como para denunciar públicamente aquello que era moroso e ineficiente en los años subsecuentes en los que una nueva educación en Minas luchaba para afirmarse.

Podemos resaltar aun dos puntos relevantes entre los aspectos del ambiente intelectual republicano y la práctica de Firmino Costa, el primero es la insociabilidad de la dimensión política e intelectual presente de forma prácticamente incontestable entre todos los miembros del período, esto significa que las acciones políticas eran necesariamente sustentadas y articuladas por actividades intelectuales y viceversa, a punto de no poder separarse una de la otra. De acuerdo con Alonso, "[...] los miembros del movimiento intelectual fueron participantes activos del debate político. Fue en busca de recursos para la comprensión de la coyuntura y de armas para la lucha política que esos grupos recurrieron a un nuevo repertorio intelectual $[\ldots]^{\prime \prime} .{ }^{18}$

A ejemplo de lo que aconteció con el movimiento contestador prerepublicano y que habría contribuido a la formación de Firmino Costa, su actuación educativa siempre estuvo informada por la óptica de aglutinación de la dimensión política e intelectual. En nuestro modo de ver, su posición de político e intelectual condicionó la actuación como educador, como fue, por su vez, condicionada por esta. Esto nos permite afirmar que la acción educativa estaba imbuida de la causa social, era la expresión de un compromiso, que él mismo se propuso, con las transformaciones sociales y políticas necesarias para la construcción de la ansiada patria, en los padrones de modernidad y desarrollo exigidos por las nuevas racionalidades.

El segundo punto es el hecho de que era recurrente la participación de los intelectuales en diversos tipos de asociaciones, como forma de dar visibilidad al conjunto de las sus propuestas revolucionarias. Fuesen estas cívicas,

18 Alonso, "Idéias em movimento..., 184. 
literarias, militares, de voluntariado, perdiodísticas, dentro de muchas otras; todas tenían una intención pedagógica y de convencimiento, esto es, eran espacios de discusión de ideas o de movilización de la sociedad y representaban lo que Alonso ${ }^{19}$ llamó "solución pedagógica" para los problemas sociales y políticos.

Firmino Costa, durante la dirección del Grupo Escolar de Lavras, Ginásio de Barbacena y Escuela Normal, creó y, naturalmente, participó de diversas organizaciones de ese tipo. Basta citar el caso de "Caixa Escolar" y de la "Asistencia Escolar", y el papel que ellas tuvieron junto a la comunidad lavrense. De la misma forma, la creación del Museo y de la Biblioteca, a pesar de ser delimitados por la legislación, asumieron un carácter de propagación de la cultura en la sociedad local, como del resto de todo el grupo en sí. Para desarrollar la Biblioteca y el Museo, además de estimular la aplicación al estudio, se creó la Sociedad Infantil de Estudio, en 1915, cuyo estatuto fue por él elaborado y publicado en su noveno informe anual. Defendió la importancia del movimiento creado por el general Baden-Powel en Inglaterra, llamado de Boys Scouts, para la educación física y cívica de los jóvenes..$^{20}$ Antes de eso, participó en el club de los republicanos de Lavras y después de eso, estuvo ligado a asociaciones, principalmente educativas, de forma bastante activa, como veremos más adelante.

Por otro lado, como la mayor parte de los intelectuales y políticos republicanos, en su mayoría del mundo occidental, privilegió la prensa como forma de dar más visibilidad a las respectivas causas por las que luchó y, con eso, ponerlas en circulación. Sobre ese aspecto Firmino usó vastamente la estrategia de difusión. No solo publicó sus artículos, libros e informes en los órganos de la prensa de mayor visibilidad en el estado, sino que creó y escribió un boletín, Vida Escolar, reconocido oficialmente por el entonces secretario Carvalho Brito, cuya lectura fue recomendada, por medio de su publicación en el periódico oficial del estado Minas Gerais.

En los textos publicados era nítida la preocupación de presentar nombres e ideas de teóricos cuyos pensamientos tenían una gran validez y denotaban prestigio, a pesar de presentar necesariamente algún tipo de fidelidad

19 Alonso, "Idéias em movimento", 153, 261.

20 Juliana Cesário Hamdan, Do método intuitivo à escola ativa: o pensamento educacional de Firmino Costa, (Tese de doutorado, Faculdade de Educação da UFMG, Belo Horizonte, 2007). 172. 
ideológica. Con respecto a las fidelidades a determinadas clasificaciones o afiliaciones teóricas, Oliveira, ${ }^{21}$ considera que los intelectuales del periodo estaban mucho más preocupados en construir una nación, o aquello que la autora llama "actualización del Brasil", esto significa que la élite intelectual estaba más direccionada a "la acción política propiamente dicha, cuyo compromiso era más con la práctica que con el rigor doctrinario o teórico". De cierta forma, la autora llama la atención a la inocuidad de rotularlos, manteniéndolos contritos a uno $\mathrm{u}$ otro lugar. Todavía, resalta aun “[...] el combate al antiguo régimen y cierta dosis de fobia a Portugal eran aspectos presentes en el pensamiento de todos los que deseaban una nueva sociedad, moderna, industrial y menos autoritaria".

Intentar encuadrar a determinado intelectual o político en alguna doctrina del pensamiento, aunque él pueda de hecho asumir diversos matices de ella, no sería fructífero para comprender la complejidad de las relaciones históricas que el posicionamiento implicaría. Entretanto, al ignorarlas incurriríamos en un riesgo tan restrictivo como este. Así, buscamos en nuestro estudio la comprensión de los lugares a partir de los cuales Firmino habría formado para la producción de su acción política e intelectual.

\section{CONCLUSIÓN}

Las actividades educacionales de Firmino Costa, como director, profesor e incluso escritor, se direccionaban para la concretización de una educación que hiciese frente a los problemas de un país que, en las representaciones de los intelectuales del periodo, estaba lejos de ser una verdadera nación, sobre todo, llevándose en consideración el atraso social, político y económico. Uno de los principales instrumentos sociales que podría modificar ese estado de cosas sería la educación. Sin embargo, la educación necesaria debería ser renovada, alineada a las experiencias de los países más desarrollados y, más que eso, organizada según un sistema, un conjunto de directivas que estableciese las bases para su progreso.

La Revista de Ensino cumplió un importante papel en la conformación del escenario educacional minero en aquellos tiempos en que, estando Francisco Campos como Secretario del Interior, sobre el gobierno de Antonio Carlos,

21 Oliveira, "A questão nacional na Primeira República” 90, 94. 
entre 1926 y 1930, la educación pasaba a ejercer, de forma más eminente, la función de amoldamiento del pueblo, apuntando a un mayor control social. Francisco Campos consideraba que muchas ideas de la educación nueva atendían perfectamente a los objetivos de la educación primaria y técnica, entonces de responsabilidad del estado. Fue así que ellas servirían como referencia para la elaboración de su reforma en 1927, bautizada de Reforma Francisco Campos.

La concepción de individuo y de sociedad ocupó un lugar central en las premisas educacionales de la Reforma Francisco Campos. Las ciencias del comportamiento y la biología fueron tomadas como marcos explicativos del desarrollo humano para la conducción de un aprendizaje que considera a las necesidades propias de la infancia y a su interacción al medio social. Las referencias teóricas para fundamentar los estudios fueron apropiadas por las ideas en circulación, prevalentes en el entorno educacional brasileño. Dentro de ellas, la de los americanos, especialmente John Dewey e Kilpatrick, y europeos Decroly y Edouard Claparède, entre otros pensadores.

Para que las nuevas proposiciones educacionales alcanzasen su objetivo, todavía, Francisco Campos necesitaría contar con cierto número de educadores y técnicos dispuestos a colaborar con el proclamado progreso social a ser atingido por medio de la educación. Dentro de otras cosas, sería necesario movilizar educadores con tránsito reconocido entre el profesorado de Minas. Si podemos considerar que el intento de Francisco Campos para la educación minera alcanzó algún éxito, ciertamente fue, sobre todo, por el esfuerzo y dedicación de aquellos que estaban posicionados suficientemente cerca del gobierno y de sus políticos para que pudiesen interferir, en alguna medida, en la conformación que la legislación fue asumiendo. Al mismo tiempo, lejos lo bastante, tanto para oír los clamores del profesorado en el trato diario con los problemas que una educación en proceso de constitución presentaría, como también para transformar los reclamos en críticas y emendas exigidas por el mismo proceso. En nuestro modo de entender, era precisamente ese el lugar ocupado por Firmino Costa.

Firmino Costa, Después de dirigir el Grupo Escolar por dieciocho años, es invitado a ocupar el cargo de Rector del Internado del Gimnasio Minero, en Barbacena, en 1925. De ahí la fecha del el primer artículo publicado en la Revista de Ensino, al cual tuvimos acceso. Constatándose el éxito de sus trabajos 
en frente del establecimiento secundario para jóvenes, el educador pasa a ser invitado, con mucha frecuencia, a proferir palestras en la capital. Poco tiempo después, cuando se instala el gobierno de Antonio Carlos, es invitado a ocupar la dirección técnica del Curso de Aplicación de la Escuela Normal de Belo Horizonte y, posteriormente, asume la dirección general del referido instituto educacional, además de colaborar sistemáticamente en la reforma de la enseñanza, debatiendo los temas pedagógicos. Antes, no obstante, el educador consolida la posición de hombre nacionalmente conocido, sobre todo, en los medios educacionales. Los primeros años de la década del treinta todavía se presenciaría una activa participación en eventos de nivel nacional, como las Conferencias promovidas por la Asociación Brasileña de Educación (ABE) y se conocerían las principales obras publicadas del educador, tales como "Vocabulario analógico" (1933) y "Por la escuela activa" (1935).

\section{FUENTES}

\section{Obras sobre Firmino Costa}

Dias, Fernando Correia. A renovação da escola pública: idéias e práticas educativas de Firmino Costa. Prêmio Grandes Educadores Brasileiros: monografias premiadas 1985, Brasília: INEP, 1986.

Hamdan, Juliana Cesário. “Do método intuitivo à escola ativa: o pensamento educacional de Firmino Costa". Tese de doutorado, Faculdade de Educação da UFMG. Belo Horizonte, 2007.

Peixoto, Maria do Carmo de Lacerda, "Firmino da Costa Pereira", em Dicionário de Educadores no Brasil. Da Colônia aos dias atuais, editado por Fávero, Maria de Lourdes de Albuquerque e Britto, Jader de Medeiros. Río de Janeiro: Editora UFRJ/MEC-INEP, 1999.

Pereira, Jardel Costa. “Grupo Escolar de Lavras: produzindo uma instituição modelar em Minas Gerais (1907-1918)". Dissertação de mestrado, Faculdade de Educação da UFMG, Belo Horizonte 2005.

\section{REFERENCIAS}

Alonso, Ângela. Idéias em movimento: a geração de 1870 na crise do Brasil-Império. São Paulo: Paz e Terra, 2002.

Beireb, José Luís Benedichio. “A função social dos intelectuais”, en: Gramsci, a vitalidade de um pensamento, editado por Alberto Aggio, 45-90. São Paulo: Editora UNESP, 1998.

De Carvalho, José Murilo. A formação das almas. O imaginário da República no Brasil. São Paulo: Companhia da Letras, 1990. 
De Carvalho, Marta Maria Chagas. Molde nacional e Fôrma Cívica: Higiene, Moral e trabalho no projeto da Associação Brasileira de Educação (1924-1931). Bragança Paulista, São Paulo: EDUSF, 1998.

De Certeau, Michel. A invenção do cotidiano. Vol. 1 - Artes de Fazer, Petrópolis, Río de Janeiro: Vozes, 1994.

De Certeau, Michel. A escrita da história. Río de Janeiro: Forense Universitária, 2006.

De Faria Filho, Luciano Mendes. Dos pardieiros aos palácios: cultura escolar e urbana em Belo Horizonte na Primeira República. Passo Fundo: Editora da UPF, 2000.

Coutinho, Carlos Nelson, Gramsci, um estudo sobre seu pensamento político, Río de Janeiro: Civilização Brasileira, 1999.

Coutinho, Carlos Nelson. Marxismo e política, A dualidade de poderes e outros ensaios. São Paulo: Cortez Editora, 1994.

Gramsci, Antonio, Quaderni del cárcere. Torino: Giulio Einaudi Editore. Prima edizione “Nuova Universal Einaudi", 1975.

Mourão, Paulo Kruger. O ensino em Minas Gerais no tempo da República (1889-1930). Belo Horizonte: Centro Regional de Pesquisas Educacionais, 1962.

Oliveira, Lúcia Lippi. A questão nacional na Primeira República. São Paulo: Editora Brasiliense, 1990.

Peixoto, Ana Maria Casasanta. A educação no Brasil, anos 20. (São Paulo: Loyola, 1982).

Peixoto, Ana Maria Casasanta. Educação e Estado Novo em Minas Gerais. Bragança Paulista: EDUSF, 2003.

Vieira, Carlos Eduardo. "Cultura e formação humana no pensamento de Antonio Gramsci”. Educação e Pesquisa, São Paulo 25, 1 (jan. / jun., 1999), 55-56.

Vieira, Carlos Eduardo, "Conhecimento histórico e arte política no pensamento de Antonio Gramsci". En Pensadores Sociais e História da Educação, editado por Luciano Mendes de Faria Filho, 63-65, Belo Horizonte: Autêntica, 2005.

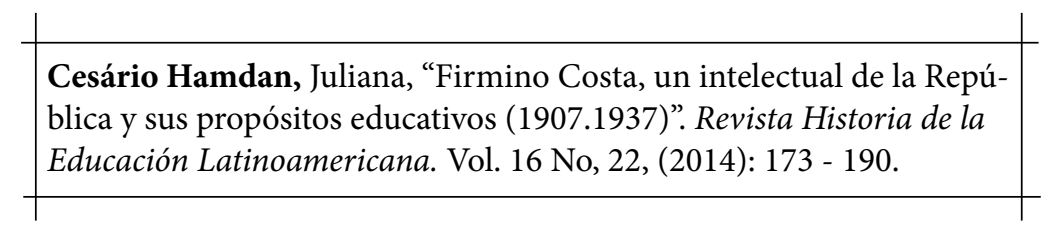

